\title{
SURFACE TOPOGRAPHICAL EFFECT OF A CAST MAGNETRON SPUTTERING TARGET ON THE COMPOSITION OF TbFeCo MAGNETO-OPTIC THIN FILMS
}

\author{
S.H. HAN, J.C. PARK, S.K. LEE, S.G. KIM and S.J. KIM* \\ Materials Design Laboratory, Korea Institute of Science and Technology, P.O. Box 131, Cheongryang, Seoul, Korea \\ *Department of Metallurgical Engineering, Seoul National, University, Sinlim-dong, Kwanak-ku, Seoul, Korea
}

\begin{abstract}
The effect of surface topographical evolution of sputtering target on the temporal variation of deposited film composition was investigated for a cast target composed of different intermetallic phases and for a sintered target composed of pure metallic phases as well as intermetallic compound. For a cast target, the preferential sputtering of $\mathrm{Tb}$ and selective erosion of $\mathrm{Tb}(\mathrm{Fe}, \mathrm{Co})_{2}$ phase were found to give the film composition variation. For a sintered target, it was caused by the selective erosion of $\mathrm{Tb}$ metallic phase compared to Fe-Co metallic phase. The angular distributions of sputtered atoms were measured. In a cast target, $\mathrm{Fe}$ and $\mathrm{Co}$ showed nearly cosine distribution and $\mathrm{Tb}$ showed undercosine distribution. In a sintered target, $\mathrm{Tb}, \mathrm{Fe}$, and $\mathrm{Co}$ all showed undercosine distribution.
\end{abstract}

KEYWORDS:MAGNETO-OPTIC DISK, CAST TARGET, SINTERED TARGET, ANGULAR DISTRIBUTION, PREFERENTIAL SPUTTERING, SELECTIVE EROSION

\section{INTRODUCTION}

Magnetron sputtering using alloy target now appears to be established as the most suitable process for the deposition of $\mathrm{TbFeCo}$ thin films for magneto-optic recording media. However, because thermo-magnetic and magneto-optic properties primarily depend on the film composition, the areal uniformity of the film composition in a disk is strictly required. In addition, variations of film composition with sputtering time should be small to achieve disk-to-disk uniformity. These two kinds of compositional uniformity are determined by the angular distribution of sputtered atoms (or depositing atoms) and its variation with sputtering time, which are controlled by target material and sputtering conditions such as sputtering gas pressure and power.

It was reported that the surface topographical change while sputtering sintered target composed of pure metallic phases and intermetallic compound gives the temporal variation of deposited film composition[1]. Because the microstructure of cast target is much different from that of sintered target, the topographical evolution on target surface might differ, which in turn affects the film composition. Furthermore, the angular distribution of sputtered atoms has been known to be quite different depending on the target[2].

In this study, the effect of the surface topographical change with sputtering time on the film composition was investigated for cast target composed of different kinds of intermetallic compounds and for sintered target composed of intermetallic compound as well as pure metallic phases. Moreover, the angular distribution of sputtered atoms from each target were measured.

\section{EXPERIMENTAL}

Two kinds of sputtering target were used in this experiment. One was 6" $\phi \mathrm{Tb}_{26} \mathrm{Fe}_{60} \mathrm{Co}_{14}$ alloy target made up of 16 pieces of cast tiles. The other one was 6" $\phi \mathrm{Tb}_{23} \mathrm{Fe}_{64} \mathrm{Co}_{13}$ alloy target made from sintering process with final intermetallic compound volume of $35 \sim 45 \%$ and $\mathrm{Tb}$, (Fe-Co) metallic phases.

To investigate the surface topographical change while sputtering, several chips of $8 \mathrm{~mm} \mathrm{x}$ $8 \mathrm{~mm} \times 1 \mathrm{~mm}$ size were prepared from the same target materials, which were glued on the target with silver paint after polishing. Before sputtering, the chip surface was observed with SEM (scanning electron microscope) as well as optical microscope. EPMA (electron probe microanalysis) was used to investigate the cast target composition. The chip 
surfaces were investigated with SEM after detaching from target intermittently.

Films were deposited on glass substrates at typical sputtering conditions: $8 \times 10^{-7}$ Torr base pressure, $2 \times 10^{-3}$ Torr sputtering Ar pressure, 240 W DC power $(240 \mathrm{~V}, 1 \mathrm{~A})$ for the cast target and $270 \mathrm{~W}$ DC power $(270 \mathrm{~V}, 1 \mathrm{~A})$ for the sintered target, and target-to-substrate distance of $142 \mathrm{~mm}$. The film composition just above the target center was measured with ICP (inductively coupled plasma spectroscopy).

The angular distributions of sputtered atoms were investigated by measuring the thickness and compositions of the films deposited at multiple locations right above the target center as illustrated in Fig. 1. 5 samples of size $10 \mathrm{~mm} \mathrm{x} 10 \mathrm{~mm} \times 1$ $\mathrm{mm}$ were hung with 3 carbon fibers under the substrate holder right on the target axis. Each location corresponds to a specific angle from target normal assuming the magnetron as a ring source.

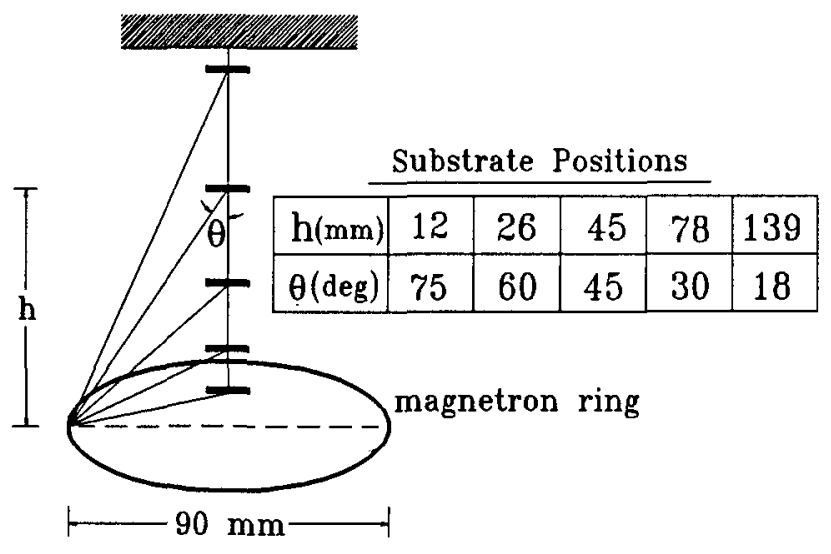

Fig. 1. The schematic diagram of the geometry for the angular distribution measurement.

\section{RESULTS AND DISCUSSION}

As can be seen in Fig. 2 (a), the cast target was composed of two phases, i.e. platelike $\mathrm{Tb}$ $(\mathrm{Fe}, \mathrm{Co})_{2}$ in $\mathrm{Tb}(\mathrm{Fe}, \mathrm{Co})_{3}$ matrix, which was confirmed by EPMA result in Table 1 . The variation of film composition with sputtering time was measured for the films deposited at $142 \mathrm{~mm}$ above the target center and is shown in Fig. 3. It can be noted that $\mathrm{Tb}$ is steadily decreasing after steep drop in 30 minutes. Fe increases steadily after

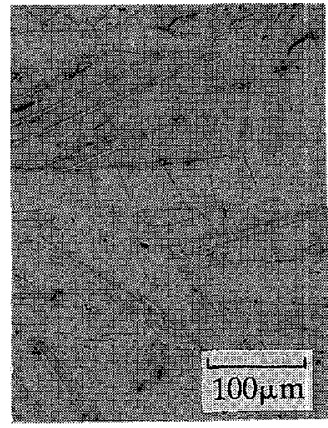

(a)

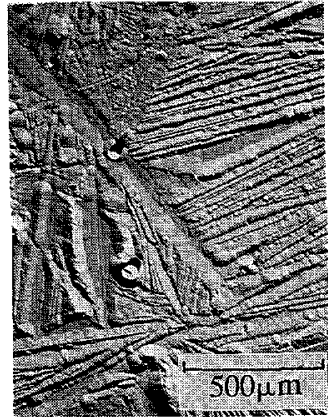

(b)
Fig. 2. (a) Optical micrograph of the cast target surface before sputtering.

(b) SEM micrograph of the cast target surface after 6 hour sputtering.

Tab. 1. Phase analysis results of the cast target with EPMA.

\begin{tabular}{|c|c|c|c|}
\hline & $\mathrm{Tb}$ & $\mathrm{Fe}$ & $\mathrm{C}_{0}$ \\
\hline $\mathrm{Tb}\left(\mathrm{Fe}, \mathrm{C}_{0}\right)_{2}$ & 34.5 at.\% & 50.9 at.\% & 14.6 at.\% \\
\hline $\mathrm{Tb}(\mathrm{Fe}, \mathrm{Co})_{3}$ & 26.6 at.\% & 60.0 at.\% & 13.4 at. $\%$ \\
\hline
\end{tabular}

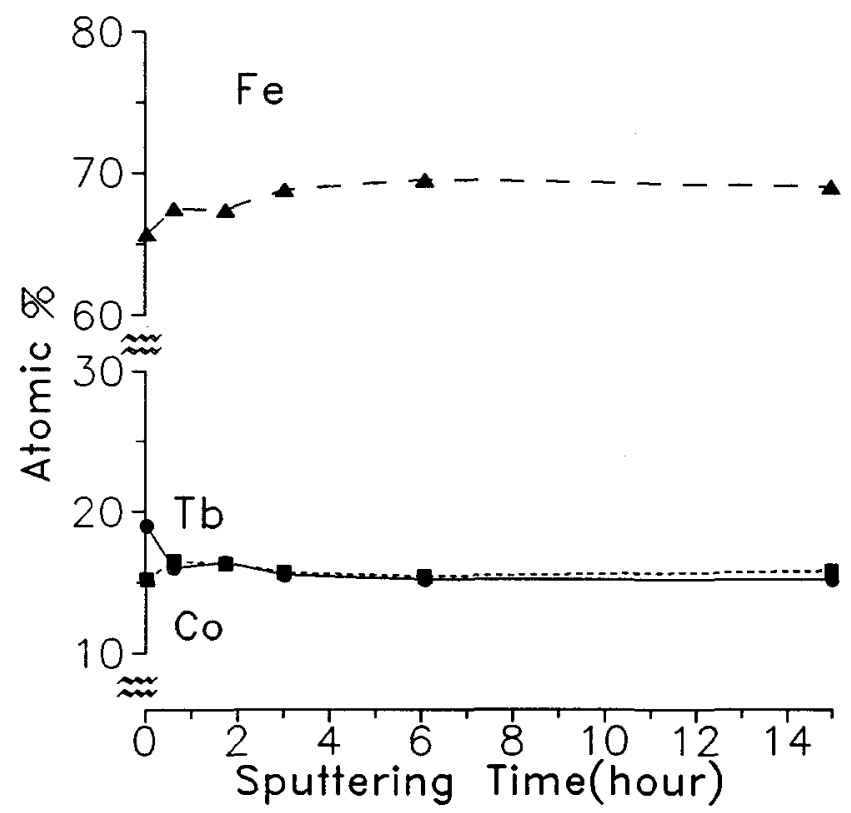

Fig. 3. Temporal variation of film composition deposited from the cast target.

initial rise. Co shows Fe-like behavior initially followed by $\mathrm{Tb}$-like behavior. The film composition remained stable after sputtering for 5 hours at about 16 at. $\% \mathrm{~Tb}$, which is much lower than $\mathrm{Tb}$ composition in the target due to rather large targetto-substrate distance used in this experiment. The 
large compositional change in films during initial 30 minutes indicates the preferential sputtering of $\mathrm{Tb}$ compared to $\mathrm{Fe}$ and $\mathrm{Co}$. The preferential sputtering of rare earth component was reported for Gd-Co film[3]. The compositional change after 30 minutes could be explained with the surface topographical change while sputtering. Fig. 2 (b) shows SEM micrograph of target surface after 6 hour sputtering. It is clearly seen that $\mathrm{Tb}(\mathrm{Fe}, \mathrm{Co})$ ${ }_{2}$ phase was eroded more than $\mathrm{Tb}(\mathrm{Fe}, \mathrm{Co})_{3}$ phase, which caused the steady decrease of $\mathrm{Tb}$ and the increase of $\mathrm{Fe}$ content in the film due to the increase of effective area of $\mathrm{Tb}(\mathrm{Fe}, \mathrm{Co})_{3}$ phase. Furthermore, the decrease of $\mathrm{Co}$ in the film can be explained by the fact that $\mathrm{Tb}(\mathrm{Fe}, \mathrm{Co})_{2}$ contains higher $\mathrm{Co}$ content than $\mathrm{Tb}(\mathrm{Fe}, \mathrm{Co})_{3}$.

In Fig. 4, the compositional change of film deposited at $142 \mathrm{~mm}$ above target center was shown for the sintered target. During 5 hours of initial sputtering, $\mathrm{Tb}$ was steadily decreasing but $\mathrm{Fe}$ and $\mathrm{Co}$ were increasing. Murakami et. al. have reported that it is caused by the selective erosion of $\mathrm{Tb}$ metallic phase resulting in the increase of exposed area containing ( $\mathrm{Fe}-\mathrm{Co}$ ) metallic phase[1]. The SEM micrographs of target surface after sputtering for 10 minutes and for 6 hours were shown in Fig. 5. Many (Fe-Co) hillocks were found after 6 hour sputtering, which were not found on

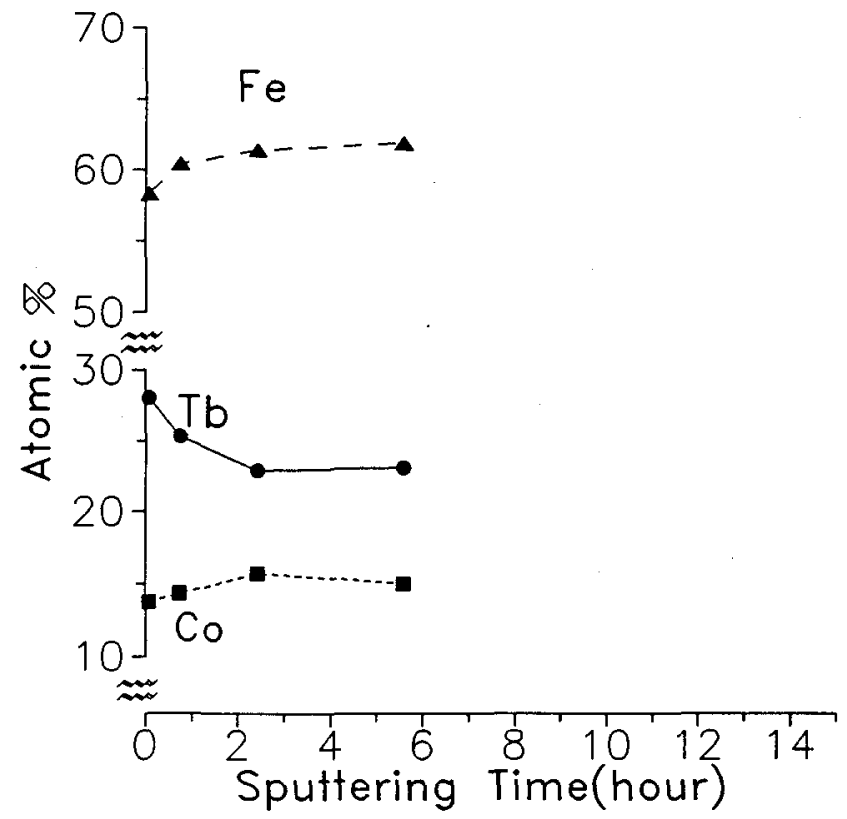

Fig. 4. Temporal variation of film composition deposited from the sintered target.

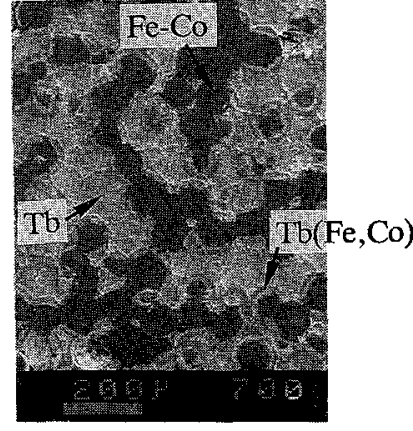

(a)

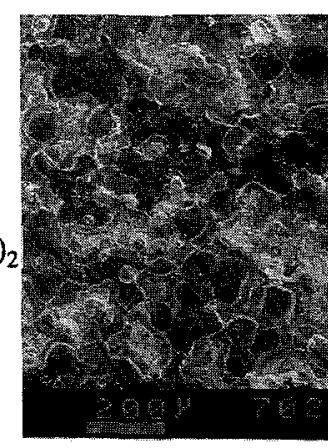

(b)
Fig. 5. SEM micrographs of the sintered target surface (a) after 10 min. sputtering (b) after 6 hour sputtering.

the target surface after 10 minute sputtering. In addition, unidentified regions between black (FeCo) particles were found, which are to be examined further if there is any contamination effect of $\mathrm{Tb}$ phase with (Fe-Co)[4].

Using the method described in previous section, the angular distributions of sputtered atoms from the cast target and the sintered target were measured and shown in Fig. 6 and Fig. 7. In the cast target $\mathrm{Fe}$ and $\mathrm{Co}$ are shown to have near-cosine distribution a little enhanced in forward direction. $\mathrm{Tb}$ shows undercosine distribution. In contrast to our result, Murakami et. al. reported undercosine distribution for both $\mathrm{Tb}$ and $\mathrm{Fe}$ from sintered $100 \%$ intermetallic $\mathrm{TbFe}$ target[5]. This discrepancy might be due to the difference in target material or measuring technique. For the sintered target, all elements showed undercosine distribution as can be seen in Fig. 7. It was reported that the metallic $\mathrm{Tb}$ has overcosine distribution and $\mathrm{Fe}$ and $\mathrm{Co}$ have undercosine distributions[2]. Because the sintered target is composed of pure metallic phases as well as intermetallic compound, the angular distribution of $\mathrm{Tb}$ should have less undercosine distribution compared to that in the cast target. However, $\mathrm{Fe}$ and $C o$ should remain the undercosine distribution.

\section{CONCLUDING REMARKS}

The temporal variation of film composition deposited with a cast target can be qualitatively explained by the preferential sputtering of $\mathrm{Tb}$ and selective erosion of $\mathrm{Tb}(\mathrm{Fe}, \mathrm{Co})_{2}$ phase while 


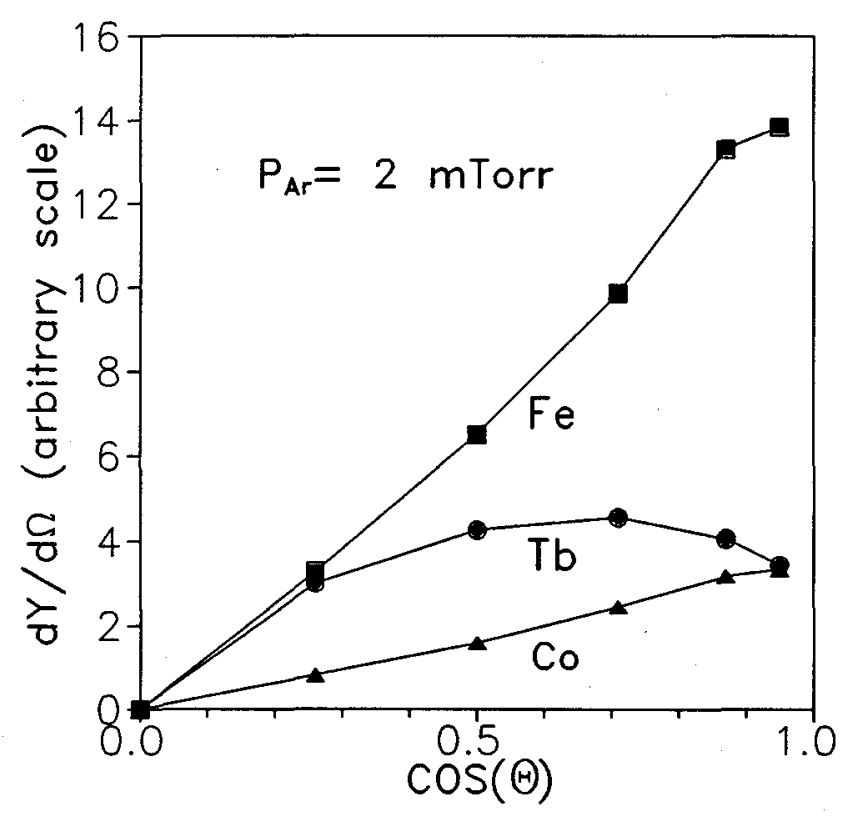

Fig. 6. Angular distribution of sputtered atoms from the cast target. $(\mathrm{dY} / \mathrm{d} \Omega$ denotes the differential sputtering yield per unit solid angle.)

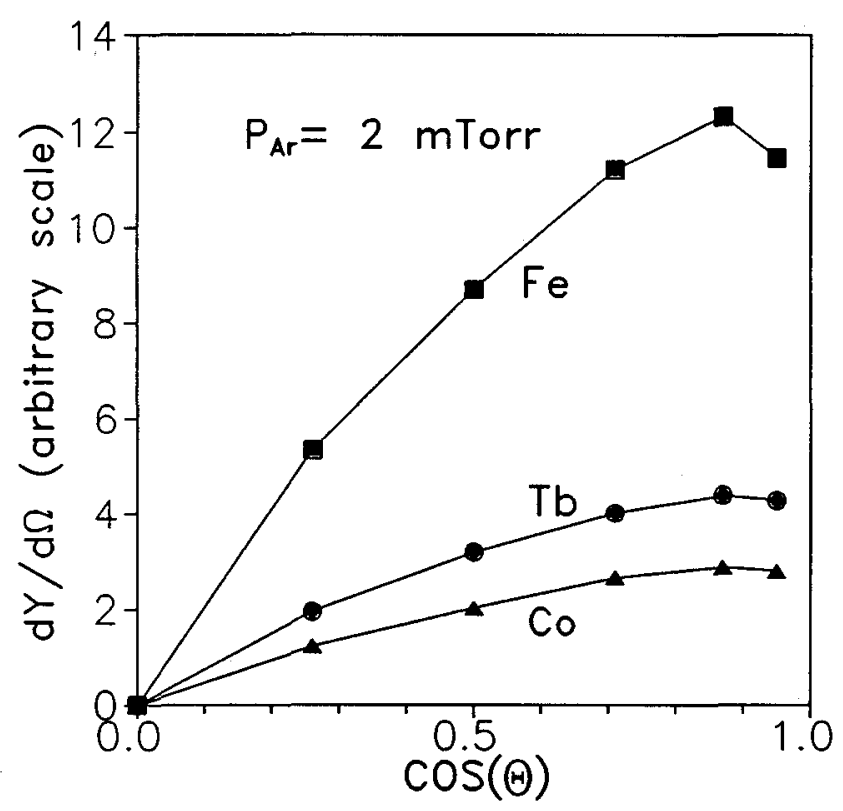

Fig. 7. Angular distribution of sputtered atoms from the sintered target.

sputtering. For a sintered target used in this work, the selective erosion of $\mathrm{Tb}$ metallic phase compared to $(\mathrm{Fe}-\mathrm{Co})$ metallic phase causes the temporal variation. The angular distributions of sputtered atoms from a cast target composed of $100 \%$ intermetallic compound were nearly cosine distribution for $\mathrm{Fe}$ and $\mathrm{Co}$ but undercosine distribution for $\mathrm{Tb}$. For a sintered target composed of pure metallic phases as well as intermetallic compound, all of $\mathrm{Tb}, \mathrm{Fe}$ and $\mathrm{Co}$ showed undercosine distributions.

\section{ACKNOWLEDGMENT}

The authors are grateful to Johnson Matthey REP. for donation of the cast alloy target and Mr. C. W. Hall for EPMA analysis as well as valuable discussions.

\section{REFERENCES}

[1] Y. Murakami, T. Shingyoji, and K. Hijikata: J. Vac. Sci. Technol., A 8(1), 7(1990).

[2] Y. Murakami, T. Shingyoji, and K. Hijikata: J. Appl. Phys., 68 (4), 1866(1990).

[3] T. Katayama, Y. Koizumi, M. Hirano, and T. Tsushima: J. Phys. Soc. Japan, 42, 1057(1977). [4] S. G. Kim, S. K. Lee, J. C. Park, C. J. Kim, and M. R. Lee: KAIST Res. Rep. to MOST, 2N 409-3258-1, 1988,p.66.

[5] Y. Murakami, T. Shingyoji, and K. Hijikata: Digests of the 10th Annual Conference on Magnetics in Japan, Magnetic Society of Japan, Tokyo, Japan, 1986,p.128. 